\title{
Analisis Hubungan Clinical Autonomy Terhadap Kepuasan Kerja Dokter Spesialis Obstetri dan Ginekologi Dalam Tindakan Seksio Sesarea Pada Sistem Jaminan Kesehatan Nasional
}

\author{
Nasrudin A.M ${ }^{1}$, Ova Emilia ${ }^{2}$, Soerjo Hadijono ${ }^{3}$, Umar Malinta ${ }^{4}$, Mohammad Hakimi $^{5}$, Soetrisno ${ }^{6}$, Eddy Tiro ${ }^{7}$ \\ Medical Faculty, Universitas Muslim Indonesia ${ }^{1}$, Faculty of Medicine, Gajah Mada University ${ }^{2}$, Faculty of Medicine, Diponegoro \\ University ${ }^{3}$, Faculty of Medicine, Hasanuddin University ${ }^{4}$, Faculty of Medicine, Gadjah Mada University ${ }^{5}$, Faculty of Medicine, \\ Sebelas Maret State University ${ }^{6}$, Faculty of Medicine, Hasanuddin University ${ }^{7}$ \\ Korespondensi: ernase@yahoo.co.id
}

Submisi: 2 September 2019; Revisi: 15 Desember 2019; Penerimaan: 23 Desember 2019

\begin{abstract}
Background: In Indonesia, the National Health Insurance System (NHIS) is an implementation of law No. 40 of 2004 on the National Social Insurance System in health sector with universal health coverage (UHC) concept. Therefore, the satisfaction of specialist's work will be very influence towards hospital works. The previous research (Nasruddin, 2017) about factor analysis related to job satisfaction of doctor specialist for obstetrics and gynecology (OBGYN) toward Sectio Caesarea (SC) on NHI showed that medical service (transparency and remuneration) and working condition have significant correlation towards work satisfaction of doctor OBGYN in SC on NHI.

Objective: to analyze the correlation of clinical autonomy on job satisfaction of doctor OBGYN on Sectio Caesarea on National Health Insurance system. Method: A quantitative research by applying analytic observational study with cross sectional design. This research was conducted in Makassar. A number of sample was 73 doctors SpOG. Data was obtained by clinical autonomy questionnaire having been tested its validity and reliability. The result of the research was analyzed by using chi-square test.

Results and Discussion: Based on the correlation of characteristics towards work satisfaction of doctor OBGYN in SC on National Health Insurance system found that age category between $36-45$ years old is satisfied, female is satisfied, working duration more than 5 years is dissatisfied and public hospital status is dissatisfied. There is no correlation between clinical autonomy in this case is control overwork ( $p=0.170)$ and prerogative obtain need service $(p=0.240$ ) on job satisfaction of doctor OBGYN in Sectio Caesarea on National Health Insurance System.

Conclusion: There is no relation between clinical autonomy on job satisfaction of doctor OBGYN in Sectio Caesarea on National Health Insurance System. Even though the doctors SpOG are not satisfied with NHI (medical service and working condition) but the doctors are able to work professionally with clinical autonomy.
\end{abstract}

Keywords: clinical autonomy; doctor OBGYN; National Health Insurance System

\begin{abstract}
ABSTRAK
Latar Belakang: Di Indonesia Sistem Jaminan Kesehatan Nasional (SJKN) merupakan implementasi dari UU Nomor 40 Tahun 2004 tentang Sistem Jaminan Sosial Nasional (SJSN) di bidang kesehatan dengan konsep Universal Health Coverage (UHC). Jaminan Kesehatan Nasional merupakan program Pemerintah Indonesia yang bertujuan untuk meningkatkan derajat kesehatan seluruh masyarakat Indonesia. Dalam menjalankan program JKN dokter spesialis mempunyai peran penting bagi rumah sakit. Oleh karena itu, kepuasan dokter spesialis sangatlah berpengaruh terhadap kinerja rumah sakit. Penelitian sebelumnya (Nasrudin, 2017) tentang analisis faktor yang berhubungan dengan kepuasan kerja dokter spesialis obstetri dan ginekologi (SpOG) terhadap tindakan seksio sesarea (SC) pada SJSN didapatkan bahwa jasa medik (transparansi dan remunerasi) dan kondisi kerja paling berhubungan dengan kepuasan kerja dokter SpOG dalam tindakan SC pada SJKN.
\end{abstract}

Tujuan: Menganalisis hubungan clinical autonomy terhadap kepuasan kerja dokter SpOG terhadap tindakan seksio sesarea pada SJKN.

Metode: Penelitian kuantitatif menggunakan studi observasional analitik dengan desain cross sectional study. Penelitian dilakukan di kota Makassar. Jumlah sampel yaitu sebanyak 73 dokter SpOG. Data diperoleh dengan menggunakan kuesioner clinical autonomy yang telah diuji Validitas dan realibilitas. Hasil penelitian di analisis menggunakan uji Chi-Square.

Hasil dan Pembahasan: Berdasarkan hubungan karakteristik terhadap kepuasan kerja dokter SpOG dalam tindakan SC pada SJKN didapatkan: umur mayoritas berada pada umur 36-45 tahun yang merasa puas, jenis kelamin dominan adalah perempuan yang merasa puas, masa kerja mayoritas $>5$ 
tahun yang merasa tidak puas, dan status rumah sakit mayoritas di rumah sakit negeri yang merasa tidak puas. Tidak ada hubungan antara clinical autonomy dalam hal ini control over work $(p=0.170)$ dan prerogative obtain need service $(p=0.240)$ terhadap kepuasan kerja dokter SpOG dalam tindakan SC pada SJKN.

Kesimpulan: Tidak ada hubungan antara clinical autonomy terhadap kepuasan kerja dokter dokter SpOG dalam tindakan SC pada SJKN, yaitu walaupun dokter SpOG tidak puas dengan SJKN (Jasa medik dan kondisi kerja) tetapi dokter masih mampu bekerja secara profesional dengan clinical autonomy.

Kata kunci: Clinical autonomy, SpOG, SJKN

\section{PENDAHULUAN}

Di Indonesia Sistem Jaminan Kesehatan Nasional (SJKN) merupakan implementasi dari UU Nomor 40 Tahun 2004 tentang Sistem Jaminan Sosial Nasional (SJSN) di bidang kesehatan dengan konsep Universal Health Coverage (UHC) yang memaksa pesertanya mengikuti sistem rujukan untuk mendapatkan pelayanan kesehatan komprehensif, murah, terjangkau, namun berkualitas. Diberlakukannya SJSN ini jelas menuntut dilakukannya peningkatan akses dan mutu pelayanan kesehatan, baik pada fasilitas kesehatan tingkat pertama maupun fasilitas kesehatan tingkat lanjutan, serta perbaikan sistem rujukan pelayanan kesehatan. ${ }^{1,2}$

Pada awal Januari tahun 2014 telah diterapkan Sistem Jaminan Kesehatan Nasional (SJKN), sesuai dengan Sistem Jaminan Sosial Nasional, dalam buku pegangan Sosialisasi Jaminan Kesehatan Nasional, memaparkan bahwa penerapan JKN akan menyebabkan perubahan fundamental pada berbagai aspek yang terkait dengan industri kesehatan di tanah air. Kemenkes RI. ${ }^{3}$

Profesi dokter sebagai tulang punggung sistem pelayanan kesehatan nasional juga akan memasuki era baru, era pembayaran mengikuti kaidah asuransi kesehatan sosial, dokter tidak bisa menentukan tarifnya secara sepihak, tarifnya akan ditentukan oleh BPJS setelah bernegosiasi dengan asosiasinya, metode pembayaran ke fasilitas kesehatan telah pula ditetapkan, yaitu secara INA-CBG dan Kapitasi, kedua metode ini memiliki filosofi yang sama, yaitu mentransfer risiko ke fasilitas kesehatan yang berarti dokter ikut menanggung risiko biaya ia memberikan pelayanan tidak sesuai dengan prosedur yang telah ditetapkan, hal ini akan mendorong terjadinya perubahan perilaku dan cara dokter menjalankan praktik kedokteran, Suci Angela. ${ }^{4}$

Kepuasan kerja merupakan faktor penting yang dapat mempengaruhi performa organisasi atau kualitas pelayanan rumah sakit. Sebagian besar kegiatan suatu organisasi kesehatan atau organisasi pelayanan kesehatan berlangsung melalui proses interaksi antara petugas dengan kliennya (pasien). Kualitas interaksi yang terjadi akan dipengaruhi oleh sikap kerja petugasnya dalam memberikan pelayanan (sikap positif petugas terhadap seluruh aktivitas organisasi). Dengan kata lain kualitas interaksi tadi akan dipengaruhi oleh kepuasan kerja petugas khususnya dokter spesialis, Evi Alwini. ${ }^{5}$

Beberapa penelitian telah menunjukkan bahwa otonomi mempengaruhi kepuasan kerja. kepuasan kerja dipengaruhi oleh karaketristik pekerjaan itu sendiri yang meliputi skill variety, task identity, task significance, autonomy dan feed back. ${ }^{2,6}$

Otonomi dokter menurut mengandung pengertian bahwa dokter seharusnya mempunyai kebebasan penuh untuk melakukan pengobatan terhadap pasien sesuai dengan the best judgment. ${ }^{7}$

Prinsip otonomi berkaitan dengan profesionalisme dalam beberapa level. Otonomi pada level kolektif berkaitan dengan kemampuan sebuah profesi untuk mengontrol standar sebagai bentuk pekerjaan, misalnya otonomi level peer group. Sedangkan professional autonomy pada level individu tidak hanya meliputi beberapa aspek pekerjaan yang diterima dari ahli medis seperti membuat keputusan klinik (clinical decision making), dan kemampuan melakukan pelayanan medik sesuai kebutuhan pasien (clinical or technical autonomy) namun juga mempunyai prerogative dalam mengontrol pekerjaan (autonomy ones schedule), Stoddard et al. ${ }^{8}$

Dokter kehilangan professional otonominya dibawah managed care. Professional (clinical) autonomy dikompromikan di bawah managed care, seperti seringkali harus meminta persetujuan sebelum memulai perawatan, hanya meresepkan obat yang diotorisasi, mengikuti rencana pengobatan 
spesifik untuk penyakit tertentu, Mckinlay and Stoeckle. ${ }^{9}$

Bahkan dengan managed care, otonomi dokter terancam saat membuat keputusan berkenaan kondisi pekerjaannya, tertekan terhadap schedulenya, menerima pembayaran kapitasi atau third party (INA CBGs).

Perubahan otonomi dokter konsisten dengan perubahan kebijakan managed care. Perubahan ini terutama pada kontrol hospitalisasi dan penggunaan beberapa tes dan prosedur yang konsisten dengan penurunan otonomi dokter. Peneliti ini juga melaporkan rendahnya otonomi dokter era 1996 (managed care) dibanding era 1991. Didapatkan sedikitnya kebebasan waktu dengan pasien, hospitalisasi pasien, review latar belakang penyakit dan tes, kepedulian terhadap pasien tidak mampu serta penggunaan sumber daya, Burdi and Baker. ${ }^{10}$

Rumah Sakit merupakan salah satu institusi yang bergerak di bidang pelayanan kesehatan yang dalam perkembangannya telah mengalami banyak kemajuan dan perubahan, baik perubahan dalam mind set maupun perubahan dalam sistem pelayanan. Pada awal perkembangannya, rumah sakit merupakan badan atau lembaga yang berfungsi sosial, tetapi perkembangan saat ini dengan adanya tuntutan masyarakat akan kualitas pelayanan yang lebih baik, berkembang pesatnya rumah sakit swasta, terbentuknya masyarakat ekonomi asean (MEA) di mana rumah sakit asing dapat masuk ke Indonesia, akan menjadikan rumah sakit lebih mengacu sebagai suatu industri yang bergerak dalam bidang pelayanan kesehatan dengan melakukan pengelolaan yang berdasar pada manajemen sebagaimana halnya badan usaha, Wiyono. ${ }^{11}$

Penerapan JKN sebagai asuransi kesehatan masih memiliki beberapa masalah dalam implementasinya, salah satunya tarif INA CBGs yang dianggap rendah menyebabkan besaran biaya yang dibutuhkan tidak sesuai dengan pelayanan yang harus diberikan oleh tenaga kesehatan, sehingga mengakibatkan ketidakpuasan dokter terhadap BPJS, Latifa. ${ }^{12}$

Indonesia sebagai negara dengan jumlah penduduk yang sangat besar memiliki masalah di bidang kesehatan yang cukup kompleks. Salah satu fenomena kesehatan yang ada di Indonesia adalah tingginya angka kematian ibu dan bayi. Setiap tahun sekitar setengah juta perempuan dan satu setengah juta bayi baru lahir kehilangan nyawa dikarenakan komplikasi yang terjadi pada persalinan. Kemudahan akses dan ketepatan waktu dalam menjangkau fasilitas medis untuk mendapatkan pelayanan pertolongan kedaruratan obstetri dan bayi baru lahir sangat penting untuk menyelamatkan keduanya dari ancaman kejadian komplikasi, Manuaba. ${ }^{13}$

Seksio sesaria adalah persalinan melalui sayatan pada dinding abdomen dan uterus yang masih utuh dengan berat janin $>1000$ gram atau kehamilan >28 minggu. Operasi seksio sesarea dilakukan jika persalinan pervaginam mengandung risiko yang lebih besar bagi ibu maupun janin. Indikasi operasi seksio sesarea dapat bersifat mutlak maupun relatif. Suatu tindakan untuk melahirkan bayi dengan berat di atas 500 gram, melalui sayatan pada dinding uterus yang masih utuh (intact), Wiknjosastro, Manuaba. ${ }^{13,14}$

Perluasan indikasi melakukan seksio sesarea dan kemajuan dalam teknik operasi dan anastesi serta obat-obat antibiotika menyebabkan angka kejadian seksio sesarea dari periode ke periode meningkat. Hal ini tergambar dari frekuensi seksio sesarea, pada tahun 2008 dilaporkan di dunia ini wanita melahirkan dengan seksio sesarea meningkat 4 kali dibandingkan 10 tahun sebelumnya, dilihat dari angka kejadian seksio sesarea dilaporkan di Amerika serikat persalinan dengan seksio sesarea sebanyak $35 \%$ dari seluruh persalinan dan Asia $28 \%$, di Indonesia berdasarkan survey demografi dan kesehatan tahun 2009-2010 mencatat angka persalinan seksio sesarea secara nasional berjumlah kurang lebih $20,5 \%$ dari total persalinan. Seksio sesarea berdampak terhadap perkembangan walau tidak memiliki kondisi medis paling banyak disebabkan oleh adanya ketakutan menghadapi persalinan normal, selain itu juga karena faktor usia dan paritas, Anggraeni. ${ }^{15}$

Berdasarkan data di beberapa rumah sakit yang ada di Kota Makassar, jumlah Seksio sesaria pada tahun 2015-2016 diantaranya, di RSKDIA Pertiwi Makassar sebanyak 1.808 pasien; di Rumah Sakit Wahidin Sudirohusodo sebanyak 532 pasien; di RSUD Kota Makassar sebanyak 216 pasien, di RSKDIA Siti Fatimah sebanyak 1.239 pasien, di RSU 
Ibnu Sina sebanyak 283 pasien dan di RSIA St Khadija 1 Muhammadiyah Cabang Makassar tindakan seksio sesarea sebelum era BPJS adalah 774-943 orang dan setelah pelayanan pasien BPJS juga sangat meningkat yaitu 1.457-2.556, Rahman. ${ }^{16}$

Sebagai data awal, peneliti memperoleh informasi bahwa sejak bulan januari 2014 hingga Maret 2018 ini, keluhan dokter Spesialis Obgin terkait tindakan seksio sesarea pada pasien BPJS dengan sistem klem berdasarkan diagnosis pada koding INA CBG dan jasa medis berdasarkan paket.

Pada penelitian sebelumnya telah melakukan penelitian tentang analisis faktor yang berhubungan dengan kepuasan kerja dokter spesialis obstetri dan ginekologi terhadap tindakan seksio sesarea pada sistem Jaminan Kesehatan Nasional. Pada penelitian ini didapatkan bahwa ada hubungan antara jasa medic dalam hal ini transparansi dan remunerasi serta kondisi kerja terhadap kepuasan kerja dokter Spesialis Obstetri dan Ginekologi dalam tindakan seksio sesarea pada Sistem Jaminan Kesehatan Nasional. ${ }^{17}$

\section{METODE}

Desain yang digunakan dalam penelitian ini adalah observasional analitik dengan pendekatan cross sectional yang bertujuan untuk menganalisis pengaruh clinical autonomy terhadap kepuasan kerja dokter spesialis obgin dalam tindakan seksio sesarea pada sistem JKN di Makassar. Penelitian ini di lakukan di Kota Makassar pada bulan Maret 2018.

Populasi dalam penelitian ini adalah semua Dokter Spesialis Obgin anggota POGI Cabang Makassar yang bertugas di Rumah Sakit di Kota Makassar baik RS Negeri maupun RS Swasta yaitu sebanyak 73 Dokter Spesialis Obgin.
Sampel dalam penelitian ini adalah Dokter Spesialis Obgin yang bertugas di Rumah Sakit di Makassar dengan total sampling yaitu sebanyak 73 Dokter Spesialis Obgin. Alat untuk mengukur variabel adalah kuesioner terstruktur, Kuesioner yang digunakan oleh peneliti dalam penelitian ini terdiri dari 2 kuesioner yaitu kuesioner clinical autonomy (Control over work dan prerogative obtain need services) dan kuesioner kepuasan dokter yang diadopsi dari tesis Salwa. ${ }^{18}$

\section{HASIL DAN PEMBAHASAN}

Dalam waktu pengambilan data berupa kuisioner yang telah dilaksanakan pada bulan Maret 2018, Karakteristik responden dapat dilihat pada tabel 1.

Pada hasil uji statistik distribusi frekuensi responden berdasarkan kategori umur untuk responden Dokter Spesialis Obgin di Kota Makassar, paling banyak terdapat dalam golongan umur 36-45 tahun yaitu sebanyak 22 dan paling sedikit terdapat pada golongan umur $>65$ tahun yaitu sebanyak 7 responden. Berdasarkan tabel karakteristik jenis kelamin responden Dokter Spesialis Obgin di seluruh Rumah Sakit di Kota Makassar, perempuan lebih dominan dibandingkan laki-laki yaitu sebesar 63,0\% (46 responden) sedangkan laki-laki yaitu sebesar $37,0 \%$ (27 responden). Berdasarkan tabel diatas distribusi frekuensi responden berdasarkan masa kerja sebagian besar responden memiliki masa kerja >5 Tahun yakni sebesar 75,3\% (55 responden). Sedangkan responden yang paling sedikit dengan masa kerja <1 Tahun hanya 5,5\% (4 responden). Distribusi frekuensi responden berdasarkan status rumah sakit sebagian besar responden bekerja di Rumah Sakit Negeri yakni sebesar 69,9\% (51 responden). Sedangkan sisanya berada di Rumah Sakit Swasta yakni sebesar 30,1\% (22 responden). 
Tabel 1. Distribusi frekuensi karakteristik berdasarkan umur responden dokter spesialis obgin di Kota Makassar tahun 2018

\begin{tabular}{lrr}
\hline Karakteristik Responden & $\mathbf{n}$ & $\%$ \\
\hline Umur (Tahun) & & \\
$\quad 26-35$ & 22 & 15,1 \\
$36-45$ & 21 & 30,1 \\
$46-55$ & 12 & 28,8 \\
$56-65$ & 7 & 16,4 \\
$>65$ & & 9,6 \\
Jenis Kelamin & 27 & 37,0 \\
$\quad$ Laki-laki & 46 & 63,0 \\
$\quad$ Perempuan & & 5,5 \\
Masa Kerja & 4 & 19,2 \\
$\quad<1$ tahun & 14 & 75,3 \\
1-5 tahun & 55 & \\
$>5$ tahun & & \\
Status RS & & \\
$\quad$ Negeri & 51 & 69,9 \\
Swasta & 22 & 30,1 \\
\hline Total & 73 & 100 \\
\hline
\end{tabular}

Sumber: Data primer, 2018

Contol overwork memiliki dua kategori yaitu kategori kurang mampu (nilai 6-14) dan mampu (nilai 15-24). Mayoritas responden berada pada kategori mampu yaitu sebesar $93,2 \%$ sebanyak 68 responden. Sedangkan prerogative obtain need service memiliki dua kategori yaitu kategori kurang mampu (nilai 5-12) dan mampu (nilai 13-20). Mayoritas responden berada pada kategori mampu yaitu sebesar 97,3\% sebanyak 71 responden. Dan Kepuasan kerja memiliki dua kategori yaitu kategori tidak puas (nilai 8-19) dan puas (nilai 20-32). Mayoritas responden berada pada kategori kurang puas yaitu sebesar $50,7 \%$ sebanyak 37 responden.

Tabel 2. Distribusi frekuensi responden berdasarkan variabel control over work, prerogative obtain need service dan kepuasan kerja oleh dokter spesialis obgin di Kota Makassar tahun 2018

\begin{tabular}{lrr}
\hline \multicolumn{1}{c}{ Variabel } & $\mathbf{n}$ & \multicolumn{1}{c}{$\%$} \\
\hline Control Over Work & 68 & 93,2 \\
Mampu & 5 & 6,8 \\
Kurang mampu & & \\
Prerogative Obtain Need Service & 71 & 97,3 \\
$\quad$ Mampu & 2 & 2,7 \\
$\quad$ Kurang Mampu & & \\
\hline
\end{tabular}

\begin{tabular}{llc}
\hline \multicolumn{1}{c}{ Variabel } & $\mathbf{n}$ & \% \\
\hline Kepuasan Kerja & 36 & 49,3 \\
$\quad$ Puas & 37 & 50,7 \\
$\quad$ Tidak Puas & & \\
\hline Total & 73 & 100 \\
\hline
\end{tabular}

Sumber: Data primer, 2018

Pada hasil penelitian ini hubungan variabel control over work dengan kepuasan kerja dapat dijelaskan bahwa tidak terdapat hubungan antara control over work dengan tingkat kepuasan dokter Sp.OG dalam tindakan SC di era JKN dimana kemampuan seorang dokter Sp.OG untuk melakukan kontrol terhadap pekerjaan atau hal yang berkaitan dengan keahlian medisnya dari aspek nilai professional dan praktik klinis seksio sesaria di era JKN secara umum dokter Sp.OG mampu melakukan control over work tetapi dokterSp.OG dalam tindakan seksio sesaria merasa tidak puas. Hal ini dapat dijelaskan karena pada saat melakukan control over work terhadap tindakan seksio sesaria dokter Sp.OG masih memiliki autonomi yang besar pada Freedom to make clinical decision atau kebebasan membuat keputusan klinik terkait penegakan diagnose dan pengobatan tanpa intervensi pihak lain, Adequate time atau kecukupan waktu dalam mengobati pasien, menjelaskan penyakit dan memberikan pelayanan yang berkualitas kepada pasien, dan Relationship atau mempertahankan hubungan, komunikasi dan kerjasama yang baik dengan pasien, dengan petugas kesehatan lainnya, dengan teman sejawat/ spesialis lainnya serta dengan manajemen sebagai indikatornya, namun hal ini menjadi tidak maksimal atau tidak sesuai ketika keputusan akhir terhadap diagnosis tergantung oleh verifikasi berdasarkan koding INA-CBGs dan pengobatan akhir tergantung ketersediaan obat sesuai dengan Formularium nasional. Inilah yang mendasari bahwa walaupun dokter Sp.OG merasa mampu dalam control over work tetapi sebagian besar tetap merasa tidak puas.

Hasil penelitian yang dilakukan Salwa di RS Awal Bros dan RSUD Kota Makassar menunjukkan bahwa dari 44 orang responden di RS Awal Bros sebanyak $22,7 \%$ yang memiliki control over work rendah yang merasa puas terhadap pekerjaan mereka dan sebanyak $77,3 \%$ yang memiliki control over work tinggi dan memiliki tingkat kepuasan tinggi. 
Sedangkan di RSUD Kota Makassar, dokter yang memiliki control over work rendah dan merasa puas sebesar $5 \%$ dan sebanyak $90 \%$ dokter yang memiliki control over work tinggi dan memiliki tingkat kepuasan kerja yang tinggi. Dengan demikian, dapat disimpulkan bahwa semakin tinggi control over work dokter maka kepuasan kerjanya juga semakin tinggi. ${ }^{8}$

Berdasarkan Society of General Internal Medicine Task Force pada kepuasan dokter, diidentifikasi dua pengaruh umum tentang otonomi klinis: control over work, kontrol atas pekerjaan dan secondary services, kemampuan untuk menyediakan pelayanan yang dibutuhkan. Managed Care Organization (MCO) dan berbagai health plan lainnya memiliki berbagai cara untuk mempengaruhi clinical autonomy dokter (baik positif maupun negative), misalnya persyaratan preauthorization, penggunaan insentif ekonomi yang dirancang untuk mengekang layanan biaya tinggi, formularium dan pembatasan lainnya pada peresepen obat, dan program manajemen penyakit berdasarkan protocol. Berbagai hal tersebut dilakukan dengan mengacu pada kendali mutu dan kendali biaya di setiap rumah sakit baik RS negeri maupun RS swasta yang dapat mempengaruhi kepuasan kerja dokter. Kepuasan kerja adalah suatu pernyataan emosional yang positif, yang berasal dari perkiraan pekerjaan dan pengalaman kerja seseorang. Kepuasan kerja tidak hanya dipengaruhi oleh pekerjaan semata, melainkan juga faktor faktor sosial dan diri individu karyawan itu sendiri, Gitosudarmo. ${ }^{19}$

Dokter berpersepsi bahwa mereka yang tidak memiliki control atas praktek mereka adalah yang paling mungkin untuk melaporkan ketidakpuasan baik dalam praktek mereka saat ini serta dalam karir mereka. ${ }^{6}$ Clinical autonomy adalah salah satu prediktor yang paling penting bagi kepuasan kerja, termasuk control over work dokter. Dengan melihat frekuensi control over work dan tingkat kepuasan kerja dokter di kedua rumah sakit yang tinggi maka peneliti menyimpulkan bahwa tersebut sesuai dengan teori yang dikemukakan oleh Kaplan. ${ }^{6}$

Tabel 3. Hubungan Karakteristik responden dokter spesialis obgin terhadap kepuasan kerja di Kota Makassar tahun 2018

\begin{tabular}{|c|c|c|c|c|c|c|}
\hline \multirow{3}{*}{$\begin{array}{c}\text { Karakteristik } \\
\text { Responden }\end{array}$} & \multicolumn{6}{|c|}{ Kepuasan Kerja } \\
\hline & \multicolumn{2}{|c|}{ Puas } & \multicolumn{2}{|c|}{ Tidak Puas } & \multicolumn{2}{|c|}{ Total } \\
\hline & $n$ & $\%$ & $n$ & $\%$ & n & $\%$ \\
\hline \multicolumn{7}{|l|}{ Umur (Tahun) } \\
\hline $26-35$ & 8 & 72,7 & 3 & 27,3 & 11 & 100 \\
\hline $36-45$ & 13 & 59,1 & 9 & 40,9 & 22 & 100 \\
\hline $46-55$ & 8 & 38,1 & 13 & 61,9 & 21 & 100 \\
\hline $56-65$ & 4 & 33,3 & 8 & 66,7 & 12 & 100 \\
\hline$>65$ & 3 & 42,9 & 4 & 57,1 & 7 & 100 \\
\hline \multicolumn{7}{|l|}{ Jenis Kelamin } \\
\hline Laki-laki & 13 & 48,1 & 14 & 51,9 & 27 & 100 \\
\hline Perempuan & 23 & 50 & 23 & 50 & 46 & 100 \\
\hline \multicolumn{7}{|l|}{ Masa Kerja } \\
\hline$<1$ Tahun & 3 & 75 & 1 & 25 & 4 & 100 \\
\hline 1-5 tahun & 10 & 71,4 & 4 & 28,6 & 14 & 100 \\
\hline$>5$ tahun & 23 & 41,8 & 32 & 58,2 & 55 & 100 \\
\hline \multicolumn{7}{|l|}{ Status RS } \\
\hline Negeri & 22 & 43,1 & 29 & 56,9 & 51 & 100 \\
\hline Swasta & 14 & 63,6 & 8 & 36,4 & 22 & 100 \\
\hline Total & 36 & 49,3 & 37 & 50,7 & 73 & 100 \\
\hline
\end{tabular}

Sumber: Data primer, 2018 
Pada hasil uji statistik karakteristik dilihat dari umur responden terbanyak pada umur 36-45 tahun yaitu 22 responden dan dari 22 responden tersebut terdapat 59,1\% merasa puas dan 40,9\% (9 responden) merasa tidak puas. Umur lebih dari 65 tahun adalah kelompok yang paling sedikit dengan 7 responden dengan jumlah persentase tidak puas adalah $57,1 \%$. Berdasarkan hubungan antara umur dengan kepuasan kerja dapat kita analisis bahwa kecenderungan umur dibawah 45 tahun merasa puas dengan tindakan SC di era JKN dan umur diatas 45 tahun lebih cenderung merasa tidak puas.. Sedangkan Pada hasil tabulasi silang hubungan antara jenis kelamin dengan kepuasan kerja dokter spesialis obgin di kota Makassar yang puas terhadap tindakan section sesarea pada SJKN ialah sebanyak
$63 \%$ berjenis kelamin perempuan dan yang berjenis kelamin laki-laki sebesar 37\%. Pada hasil uji statistik hubungan antara masa kerja dengan kepuasan kerja Sp.OG tampak bahwa 55 responden bekerja atau menjalankan profesi sebagai Sp.OG masa kerja $>5$ tahun dengan persentase yang tidak puas adalah $58,2 \%$ (32 responden) dan 41,8\% (23 responden) merasa puas. Sedangkan dokter Sp.OG yang menjalankan profesi masa kerja <1 tahun merasa puas dengan persentase $75 \%$ ( 3 responden) sisanya dengan persentase $25 \%$ ( 1 responden) merasa tidak puas dari total 4 responden. Serta dokter Sp.OG yang menjalankan profesi masa kerja 1-5 tahun merasa puas dengan persentase $71.4 \%$ (10 responden) sisanya dengan persentase $28.6 \%$ (4 responden) merasa tidak puas dari total 14 responden.

Tabel 4. Hubungan control over work terhadap kepuasan kerja dokter spesialis obgin di Kota Makassar tahun 2018

\begin{tabular}{|c|c|c|c|c|c|c|c|}
\hline \multirow{3}{*}{ Variabel } & \multicolumn{6}{|c|}{ Kepuasan Kerja } & \multirow{3}{*}{$p$} \\
\hline & \multicolumn{2}{|c|}{ Puas } & \multicolumn{2}{|c|}{ Tidak Puas } & \multicolumn{2}{|c|}{ Total } & \\
\hline & $\mathrm{n}$ & $\%$ & $\mathrm{n}$ & $\%$ & $\mathbf{n}$ & $\%$ & \\
\hline \multicolumn{8}{|l|}{ Control Over Work } \\
\hline Mampu & 32 & 47,1 & 36 & 52,9 & 68 & 100 & 0,170 \\
\hline Kurang Mampu & 4 & 80 & 1 & 20 & 5 & 100 & \\
\hline \multicolumn{8}{|c|}{ Prerogative Obtain Need Service } \\
\hline Mampu & 34 & 47,9 & 37 & 52,1 & 71 & 100 & 0,240 \\
\hline Kurang mampu & 2 & 100 & 0 & 0 & 2 & 100 & \\
\hline Total & 36 & 49,3 & 37 & 50,7 & 73 & 100 & \\
\hline
\end{tabular}

Sumber: Data primer, 2018 dengan nilai sig $\mathrm{p}<0,05$ menggunakan uji analisis chi-square

Berdasarkan hasil uji statistik pengaruh antara control over work dengan kepuasan dokter Sp.OG diperoleh data 68 responden merasa mampu akan control over work dengan persentase 52,9\% (36 responden) yang merasa tidak puas dan $47,1 \%$ (32 responden) merasa puas. Sedangkan 5 responden merasa kurang mampu terhadap control over work dengan persentase $80 \%$ (4 responden) merasa puas dan 20\% (1 responden) merasa tidak puas. Karena hasil hipotesis penelitian $(\mathrm{Ha})$ ditolak maka tidak terdapat pengaruh yang positif antara control over work terhadap kepuasan kerja dokter spesialis obgyn di makassar. Hasil penelitian yang dilakukan Salwa (2017) di RS Awal Bros dan RSUD Kota Makassar menunjukkan bahwa dari 44 orang responden di RS Awal Bros sebanyak 22,7\% yang memiliki control over work rendah yang merasa puas terhadap pekerjaan mereka dan sebanyak $77,3 \%$ yang memiliki control over work tinggi dan memiliki tingkat kepuasan tinggi. Sedangkan di RSUD Kota Makassar, dokter yang memiliki control over work rendah dan merasa puas sebesar $5 \%$ dan sebanyak $90 \%$ dokter yang memiliki control over work tinggi dan memiliki tingkat kepuasan kerja yang tinggi. Dengan demikian, dapat disimpulkan bahwa semakin tinggi control over work dokter maka kepuasan kerjanya juga semakin tinggi.

Berdasarkan hasil uji statistik pengaruh antara prerogative obtain need service dengan kepuasan dokter Sp.OG diperoleh data 71 responden merasa mampu terhadap prerogative obtain need service dengan persentase $52,1 \%$ (37 responden) yang merasa tidak puas dan 47,9\% (34 responden) merasa puas. Sedangkan sisanya 2 responden 
merasa kurang mampu terhadap prerogative obtain need service semuanya merasa puas. Karena hasil hipotesis penelitian ( $\mathrm{Ha}$ ) ditolak maka tidak terdapat pengaruh yang positif antara prerogative obtain need service terhadap kepuasan kerja dokter spesialis obgyn di makassar. Pada hasil penelitian ini hubungan variabel prerogative obtain need service dengan kepuasan kerja dapat dijelaskan bahwa tidak terdapat hubungan antara prerogative obtain need service dengan tingkat kepuasan dokter Sp.OG dalam tindakan SC di era JKN, dimana kemampuan prerogative seorang dokter Sp.OG dalam membuat pelayanan yang sesuai dengan kebutuhan pasien seksio sesaria di era JKN secara umum mampu melakukan prerogative obtain need service tetapi dokter Sp.OG dalam tindakan seksio sesaria merasa tidak puas. Berdasarkan penelitian sebelumnya tentang analisis faktor yang berhubungan dengan kepuasan kerja dokter spesialis obstetri dan ginekologi terhadap tindakan seksio sesarea pada sistem Jaminan Kesehatan Nasional didapatkan bahwa ada hubungan antara jasa medic dalam hal ini transparansi dan remunerasi serta kondisi kerja terhadap kepuasan kerja dokter Spesialis Obstetri dan Ginekologi dalam tindakan seksio sesarea pada Sistem Jaminan Kesehatan Nasional. ${ }^{14}$ Berdasarkan hasil uji statistik hubungan antara transparansi jasa medik dengan kepuasan dokter Sp.OG diperoleh data 53 responden menganggap transparansi jasa medik tidak transparan dengan persentase $64,2 \%$ (34 responden) yang merasa tidak puas dan 35,8\% (19 responden) merasa puas. Sedangkan 20 responden menganggap transparansi jasa medik sudah transparan dengan persentase $85 \%$ (17 responden) merasa puas dan 15\% (3 responden) merasa tidak puas. Berdasarkan hasil uji statistik hubungan antara remunerasi jasa medik dengan kepuasan dokter Sp.OG diperoleh data 54 responden menganggap remunerasi jasa medik tidak sesuai dengan persentase 68,5\% (37 responden) yang merasa tidak tidak puas dan 31,5\% (17 responden) merasa puas. Sedangkan 19 responden yang menganggap remunerasi jasa medik sudah sesuai semuanya merasa puas. Berdasarkan hasil uji statistik hubungan antara kondisi kerja dengan kepuasan dokter Sp.OG diperoleh data 57 responden menganggap kondisi kerja baik dengan persentase $59,6 \%$ (34 responden) merasa puas dan
40,4\% (23 responden) merasa tidak puas. Sedangkan 16 responden menganggap kondisi kerja kurang baik dengan persentase $87,5 \%$ (14 responden) merasa tidak puas dan $12,5 \%$ (2 responden) merasa puas. Berdasarkan hasil penelitian Nasrudin sebelumnya dikaitkan dengan hasil penelitian ini maka dapat di analisis bahwa walaupun dokter Sp.OG tidak puas dengan jasa medik (transparansi dan remunerasi) dan kondisi kerja dalam melakukan tindakan seksio sesarea namun secara profesional dokter Sp.OG masih mampu melakukan kendali terhadap clinical autonomy nya (control over work dan prerogative obtain need service) dalam melakukan tindakan SC di era JKN. ${ }^{17}$

Di RS Awal Bros dan RSUD Kota Makassar menunjukkan di RS Awal Bros sebanyak 50,0\% yang memiliki prerogative obtain need services rendah yang merasa puas dan tidak puas terhadap pekerjaan mereka. Sedangkan di RSUD Kota Makassar, dokter yang memiliki prerogative obtain need services rendah dan merasa puas sebesar dan sebanyak 90\%. dokter yang memiliki prerogative obtain need services tinggi dan memiliki tingkat kepuasan kerja yang tinggi. Dengan demikian, dapat disimpulkan bahwa semakin tinggi prerogative obtain need services dokter maka kepuasan kerjanya juga semakin tinggi sehingga berpengaruh positif, Salwa. ${ }^{18}$

Dengan menggunakan uji korelasi chi-square dapat dianalisis bahwa terdapat pengaruh positif prerogative obtain need services terhadap kepuasan dokter di kedua Rumah Sakit. Meskipun pengaruh positif ini lebih kuat di RSUD Kota Makassar dibandingkan dengan pengaruh positif di RS Awal Bros Makassar yang dilihat dari nilai koefisien korelasi.

\section{KESIMPULAN DAN SARAN}

Hasil penelitian menyimpulan bahwa berdasarkan hubungan karakteristik terhadap kepuasan kerja dokter SpOG dalam tindakan SC pada SJKN didapatkan: berdasarkan umur, mayoritas berada pada umur 36-45 tahun yang merasa puas, jenis kelamin dominan adalah perempuan yang merasa puas, masa kerja mayoritas $>5$ tahun yang merasa tidak puas, dan status rumah sakit mayoritas di rumah sakit negeri yang merasa tidak puas. 
Kemudian Tidak ada hubungan antara clinical autonomy (control over work dan prerogative obtain need service) terhadap kepuasan kerja dokter dokter SpOG dalam tindakan SC pada SJKN, yaitu walaupun dokter SpOG tidak puas dengan SJKN (Jasa medik dan kondisi kerja) tetapi dokter masih mampu bekerja secara profesional dengan clinical autonomy. Spesialis Obgin di Kota Makassar dalam menjalankan program Jaminan Kesehatan Nasional (JKN) sudah baik dan dapat dipertahankan, namun tetap perlu dilakukan evaluasi untuk meningkatkan tingkat kepuasan dokter spesialis Obgin.Kepuasan kerja dokter spesialis Obgin adalah sesuatu hal yang subjektif, sehingga diperlukan penggunaan metode kualitatif dalam pengukuran kepuasan kerja dokter spesialis Obgin.Diperlukan penelitian yang lebih luas mencakup seluruh dokter SpOG diwilayah POGI Cabang Makassar yang meliputi Sulawesi Selatan dan Sulawesi Barat.Diperlukan penelitian dan analisis selanjutnya guna memperoleh hasil yang lebih memadai dan akurat yang mencakup seluruh dokter spesialis tenaga medis lainnya dalam satu tim tindakan seksio sesarea.

\section{DAFTAR PUSTAKA}

1. Evans, D. B., HSU, J., \& Boerma, T. 2013. (UHC) Universal Health Coverage \& Universal Access, Vol. 91: 8 (2013). Pro Quest, 546. 546A.

2. Hackman, J.R. \& Oldham, G.R. 1974. The Job Diagnostic Survey: An Instrument for The Diagnosis of Jobs and The Evaluation of Job Redesign Projects [DX Reader version]. New Haven: Department of Administrative Sciences Yale University.

3. Kementerian Kesehatan Republik Indonesia. 2014. Buku Pegangan Jaminan Kesehatan Nasional (JKN) dalam Sistem Jaminan Sosial Nasional. Jakarta.

4. Diliana Suci Angela, Noor Noer Bahry, Maria Ida Leida. 2014. Kepuasan kerja dokter spesialis RS Nene Malommo Kab Sidrap dan RSUD Kota Makassar pada pelaksanaan JKN tahun 2014. Tesis Program Studi Magister IImu Kesehatan Masyarakat Konsentrasi Administrasi Rumah Sakit Program Pasca Sarjana Universitas Hasanuddin Tahun 2014.

5. Alwini Evi. 2014. Faktor-faktor yang berhubungan dengan kepuasan kerja dokter spesialis di rumah sakit Mohammad Ridwan Meuraksa Jakarta. Tesis Program Studi Magister Ilmu Kesehatan Masyarakat Konsentrasi Administrasi Rumah Sakit Program Pasca Sarjana Universitas Indonesia Tahun 2014.
6. Kaplan, D. 2009. Determinants of job satisfaction and turnover among physicians.

7. Emanuel, E. J. \& Pearson, S. D. 2012. Physician autonomy and health care reform. JAMA, 307, 367368.

8. Stoddard, J. J., Hargraves, J. L., Reed, M. \& Vratil, A. 2001. Managed care, professional autonomy, and income. Journal of general internal medicine, 16, 675-684.

9. Mckinlay, J. B. \& Stoeckle, J. D. 1988. Corporatization and the social transformation of doctoring. International Journal of Health Services, 18, 191205.

10. Burdi, M. D. \& Baker, L. C. 1997. Market-level health maintenance organization activity and physician autonomy and satisfaction. The American journal of managed care, 3, 1357-1366.

11. Wiyono, A. 2006. Studi tentang kualitas pelayanan dan kepuasan konsumen di Rumah Sakit Islam Manisrenggo Klaten. Disertasi Program Pasca Sarjana, Universitas Sebelas Maret, Surakarta.

12. Meutuah Latifa Dara, Ishak Saifuddin, 2015. Analisis kepuasan dokter spesialis terhadap program JKN di RSUD Dr. Zainoel Abidin tahun 2014. Jurnal Kedokteran Syiah Kuala Volume 15 Nomor 1.

13. Manuaba, Ida Bagus. 2012. Teknik Operasi Obstetri dan Keluarga Berencana. Jakarta: CV.Trans Info Media.

14. Wiknjosastro, H. 2005. Ilmu Kebidanan Jakarta: Yayasan Bina Pustaka Sarwono Prawirohardjo.

15. Anggraeni, A.C. 2012. Asuhan Gizi Nutrional Care Proccess. Yogyakarta: Graha Ilmu.

16. Rahman A, 2017. Persepsi kepuasan pasien BPJS Seksio sesarea terhadap pelayanan dokter SpOG di RS Ibnu Sina Makassaar.Disertasi S3, UNM, Makassar.

17. Nasrudin. 2017. Analisis Faktor Yang Berhubungan Dengan Kepuasan Kerja Dokter Spesialis Obstetri dan Ginekologi Dalam Hal Tindakan Seksio Sesarea Pada Sistem Jaminan Kesehatan Nasional. Tesis Program Studi Magister IImu Kesehatan Masyarakat Konsentrasi Manajemen Rumah Sakit Program Pasca Sarjana Universitas Hasanuddin.

18. Salwa M, 2016. Analisis Pengaruh Clinical Autonomy Terhadap Kepuasan Kerja Dokter Dalam Era Jkn Di Rs Awal Bros Makassar Dan Rsud Kota Makassar.

19. Gitosudarmo, D. 1997. Perilaku Keorganisasian Yogyakarta, BPFE. 